\section{DIARY}

\section{MAY}

National Junior Trainee Study

Day in Oral Surgery

Date: 27 May 2011

Venue: Birmingham Dental Hospital

Email: Mr Pankaj Taneja,

pan0980@hotmail.co.uk

www.jtoralsurgery.com

\section{JUNE}

iTOP: Educating your patients in the best techniques for self care during implant treatment

Date/venue:

13 June 2011 - Edinburgh Carlton Hotel

14 June 2011 - Shrigley Hall Hotel, Cheshire 15 June 2011 - Hendon Hall, London

16 June 2011 - Walton Hall Hotel,

Stratford upon Avon

Email: info@curaprox.co.uk

www.curaprox.co.uk

World Aesthetic Congress

Date: 17-18 June 2011

Venue: Business Design Centre, Islington

Telephone: 0800371652

www.independentseminars.com/wac

ITOP Introductory: developing proven strategies that can lead to more effective communication with patients

Date: 17-18 June 2011

Venue: Walton Hall, Warwickshire

Email:info@curaprox.co.uk

www.curaprox.co.uk

BACD Roadshow - A peek into the future of cosmetic dentistry

Date: 20 June 2011

Location: Belfast

Email:suzy@bacd.com

www.bacd.com

\section{STUDY WILL EXAMINE NHS IMPLICATIONS OF MEDICAL TOURISM}

The National Institute for Health Research (NIHR) is funding a research project exploring medical tourism. The purpose of the research is to examine the economic impact of medical tourism, the decision-making of those choosing to have treatment overseas - including dental treatment - and the development of the medical tourism industry.

Beyond anecdotal reports and media speculation relatively little is known about the implications for the NHS of inward or outward medical tourism. This is despite 50,000 people travelling from the UK to access treatment overseas and contributing to the growing industry around medical tourism, thought to be worth $\$ 60$ billion internationally.

The project commenced in November 2010 and will be conducted by a multidisciplinary team skilled in health economics, patient and consumer issues, quality and safety, and with an understanding of health industry development.

The data collected will form the basis for five case studies, provisionally including cosmetic surgery, elective surgery, fertility treatment, and dental services.

A project website has been developed and will be updated regularly with details on how the research is progressing: www.medicaltourismresearch.co.uk.

\section{NEW PRESIDENTS INSTALLED AT SAN DIEGO MEETING}

Jeffrey Ebersole, Professor of Oral Health Research (pictured), was installed as the 40th President of the American Association for Dental Research (AADR) at the conclusion of the Association's 40th Annual Meeting in San Diego, California on 19 March.

The meeting was held in conjunction with the 89th General Session \&t Exhibition of the International Association for Dental Research (IADR), where E. Dianne Rekow was installed as the 88th president of the IADR.

Dr Ebersole is Director of the Center for Oral Health Research and Associate Dean for Research at the University of Kentucky College of Dentistry. Dr Rekow is currently Senior Vice Provost for Engineering and Technology at New York University (NYU) and is

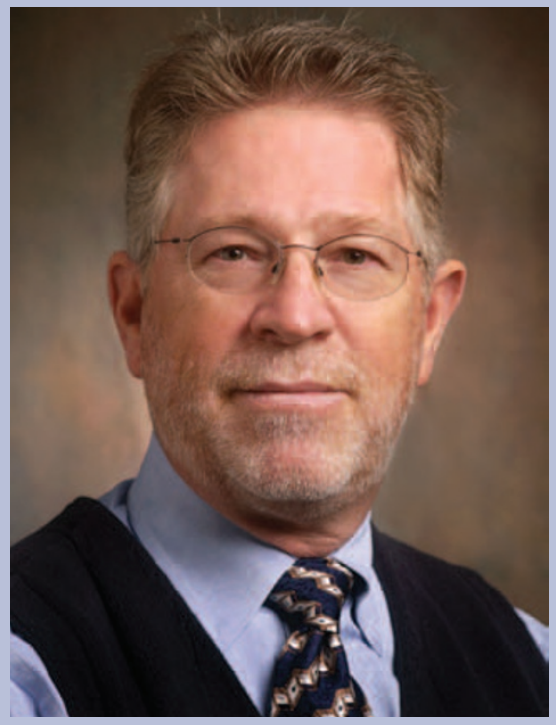

also a Professor of Orthodontics and of Basic Science and Craniofacial Biology at NYU College of Dentistry.

\title{
VOLUNTEERS TEACH TANZANIANS TO EXTRACT TEETH
}

Staff members from the community dental health service in Liverpool have returned from a two-week trip to Tanzania where they trained African Clinical Officers to extract teeth.

Liverpool Community Health NHS Trust employees Rizwana Haq, a Dental Officer, and Liz Puzzar, a Senior Dental Health Promotion Officer, volunteered their services as part of charity Bridge2Aid's Dental Volunteer Programme.
Although 75\% of Tanzania's population live in rural areas, 90\% of the country's dental personnel live in cities, leaving rural people cut off from dental and general health services and often in a lot of pain. Tanzania's Rural Clinical Officers are responsible for the provision of all basic medical services in thousands of small dispensaries and health centres across Tanzania. They regularly 